Licença CC BY: Artigo distribuído sob os termos Creative Commons, permite uso e distribuição irrestrita em qualquer meio desde que o autor credite a fonte original.

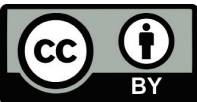

\section{ANÁLISE DA PEREGRINAÇÃO NAS FESTIVIDADES DO DIVINO PAI ETERNO EM TRINDADE/GO}

\author{
ANALYSIS OF THE PILGRIMAGE IN THE FESTIVITIES OF THE \\ DIVINE ETERNAL FATHER IN TRINDADE/GO
}

\author{
ANÁLISIS DE LA PEREGRINACIÓN EN LAS FESTIVIDADES DEL \\ DIVINO PADRE ETERNO EN TRINIDAD/GO
}

\author{
ALESSANDRO GOMES ENOQUE ' \\ LORRANA LAILA SILVA DE ALMEIDA
}
UNIVERSIDADE FEDERAL DE UBERLÂNDIA, ITUIUTABA, MINAS GERAIS, BRASIL' UNIVERSIDADE FEDERAL DE GOIÁS, GOIÂNIA, GOIÁS, BRASIL²

\begin{abstract}
RESUMO: Este trabalho objetivou compreender a peregrinação em honra ao Divino Pai Eterno em Trindade/GO, a partir das percepções dos romeiros que realizam a caminhada, considerando quatro dimensões principais: identitária, religiosa, turística e econômica. Como procedimentos metodológicos foi adotada a abordagem qualitativa, a partir de uma pesquisa de campo, exploratória e descritiva. Os instrumentos para a coleta dos dados compreenderam entrevistas semiestruturadas conduzidas por meio de um roteiro. A técnica utilizada para a análise dos dados foi a Análise de Discurso. Como resultados, a peregrinação apresenta-se como sendo um ritual marcado pelo sacrifício e pelo sofrimento daquele que empreende esta caminhada. Este, o romeiro, motivado pela fé ou pela tradição familiar, empreende esta caminhada com o objetivo de cumprir os votos pedidos ou concedidos, sejam eles de natureza econômica ou até mesmo relacionados a doenças ou de conteúdo mais cotidiano. Considerando o trajeto percorrido como sendo de natureza sagrada, o peregrino revela certo incômodo com a influência do campo econômico na esfera religiosa e tende a separar as espacialidades e temporalidades, profanas e sagradas, tanto no universo da festa quanto da caminhada.
\end{abstract}

Alessandro: Professor no Programa de Pós-Graduação em Ciências Sociais (PPGCS), Universidade Federal de Uberlândia (UFU), Uberlândia, Minas Gerais, Brasil. Professor no Programa de Pós-Graduação em Geografia do Pontal (PPGEP/PONTAL), Universidade Federal de Uberlândia (UFU - Campus Pontal), Ituiutaba, Minas Gerais, Brasil. Pós-Doutor em Sciences Humaines, Université du Québec à Montréal (UQAM), Montreal, Quebec, Canadá. Doutor em Ciências Humanas (Sociologia e Ciência Política) pela Faculdade de Filosofia e Ciências Humanas da Universidade Federal de Minas Gerais (FAFICH/UFMG). E-mail: alessandroenoque@gmail.com. Orcid: https://orcid.org/0000-0002-1766-0684

Lorrana: Mestre em Geografia, Instituto de Ciências Humanas do Pontal, Universidade Federal de Uberlândia (UFU - Campus pontal), Ituiutaba, Minas Gerais, Brasil. Doutoranda em Administração, Universidade Federal de Goiás (UFG), Goiânia, Goiás, Brasil. E-mail: lorranalailaalmeida@gmail.com. Orcid: https:// orcid.org/0000-0003-3462-7445 


\begin{abstract}
This study aimed to understand the representations of the pilgrimage in honor of the Divine Eternal Father in Trinity/GO, from the perspective of the pilgrims that undertake the walk, considering four dimensions: identity, religious, tourist and economics. As methodological procedures, the qualitative approach was adopted, based on field, exploratory and descriptive research. The data collection instruments were semistructured interviews, conducted using a script. The data analysis technique used was Discourse Analysis. As results, the pilgrimage is seen as a ritual marked by the sacrifice and suffering of the pilgrims who undertake the walk. Motivated by faith or family tradition, the pilgrims undertake this journey with the aim of fulfilling the vows requested or giving thanks for requests granted, whether related to finances, or health and diseases, or other aspects of their daily lives. Considering the route traveled as being of a sacred nature, the pilgrim reveals a certain annoyance at the encroachment of the economic field onto the religious sphere, and seeks to separate the profane and sacred spaces and temporalities, both during the festival and on the pilgrimage.
\end{abstract}

KEYWORDS: pilgrimage; pilgrim; divine; devotion; religion.

RESUMEN: Este trabajo tuvo por objeto comprender las representaciones acerca de la peregrinación en honor al Divino Padre Eterno en Trinidad/GO, en la perspectiva de los romeros que realizan la caminata, a partir de las dimensiones: identitaria, religiosa, turística y económica. Como procedimientos metodológicos, se adoptó el enfoque cualitativo, a partir de una investigación de campo, exploratoria y descriptiva. Los instrumentos para la recopilación de datos comprendieron entrevistas semiestructuradas, conducidas por medio de un itinerario. La técnica utilizada para el análisis de los datos fue el Análisis de discurso. Como resultado, la peregrinación se presenta como un ritual marcado por el sacrificio y el sufrimiento del que emprende esta caminata. Este, el romero, motivado por la fe o por la tradición familiar, emprende esta caminata con el objetivo de cumplir los votos pedidos o concedidos, ya sean de naturaleza económica o incluso relacionados a enfermedades o de contenido más cotidiano. Considerando el trayecto recorrido como de naturaleza sagrada, el peregrino revela cierta incomodidad con la influencia del campo económico en la esfera religiosa y tiende a separar las espacialidades y temporalidades profana y sagrada tanto en el universo de la fiesta como de la caminata.

PALABRAS CLAVE: peregrinación; romero; divino; devoción; religión.

\title{
INTRODUÇÃO
}

Ao buscar uma compreensão acerca das peregrinações e seus desdobramentos, a consolidação de um campo de pesquisas sobre deslocamentos motivados por devoção religiosa tem sido objeto de investigação de várias áreas do conhecimento, como a antropologia, a história, a geografia, a teologia, dentre outras (Rocha \& Belchior, 2016; Cardita, 2012; Steil \& Carneiro, 2008; Calvelli, 2006). Nesse sentido, a temática da religião, em especial o estudo da peregrinação, tem possibilitado relevantes descobertas, trazendo novos significados a essa manifestação de caráter religioso e cultural (Souza, 2018; Marques, 2017; Ribeiro, 2003; Rosendahl, 2002).

Nas menções de Antunes, Barroco e Dias (2016), bem como Rocha e Belchior (2016), a peregrinação, também entendida como romaria, distingue-se pelo caráter espiritual do ato, sendo uma prática que une religiosidade, devoção, cultura e simbolismo. Ao dissertarem sobre as raízes dessa manifestação religiosa, os autores expõem que "peregrinar" seria o mesmo que "estar a caminho", e ainda complementam a afirmativa associando a palavra peregrinação ao ato de andar, ir em direção a algo, sendo este considerado sagrado pelo senso comum. 
Apesar da relevância dessa temática e de contribuições de pesquisas acerca das peregrinações, destaca-se uma carência de trabalhos no campo de estudos organizacionais voltados à investigação do fenômeno da peregrinação, a partir das percepções de indivíduos que praticam tal manifestação de caráter religioso. Nesse sentido, são incipientes os estudos nessa área que compreendem a acepção dos romeiros quanto à realização da romaria, principalmente ao abordar elementos turísticos e de festividades católicas, considerando que a peregrinação passa a representar a devoção ao santo celebrado no contexto da festa religiosa, simbolizada na caminhada percorrida pelo romeiro.

Assim posto, dentre algumas das festividades católicas brasileiras que contemplam o fenômeno da peregrinação em sua conjuntura, destaca-se a Festa do Divino Pai Eterno, realizada anualmente na cidade de Trindade-Goiás. Trata-se de uma festividade religiosa considerada como uma manifestação cultural de ampla dimensão, que reúne mais de 3 milhões de fiéis e romeiros nos dez dias de realização, sendo o período de ocorrência compreendido no final do mês de junho e início do mês de julho de cada ano. Este evento tem como culto o "Deus Pai", em que o principal símbolo de representação consiste em uma medalha encontrada por um casal de lavradores em meados de 1840. Por sua vez, a medalha contemplava a representação da Santíssima Trindade coroando a Virgem Maria. O que começou com um culto doméstico em uma pequena capela construída na casa do casal de lavradores que encontraram a imagem, resultou na disseminação do culto à divindade religiosa na comunidade chamada Barro Preto, atual cidade de Trindade, principalmente a partir de relatos de "milagres" que teriam sido recebidos pelos devotos. Atualmente, a festa possui significativa dimensão no país e compreende um misto de atividades relacionadas à conjuntura religiosa e popular. Nesse sentido, a festa engloba a realização de missas, novenas, batizados, casamentos e romaria de carros de boi, além de contemplar jogatina, parque de diversões e danças, como o forró. Cabe destacar que um dos elementos marcantes dessa festividade são as barracas de comércio, sendo um atrativo de diferentes públicos em decorrência da diversidade de produtos que são comercializados no período da festividade, como bijuterias, confecções e produtos de utilidade doméstica (Coelho, 2021).

A festa é conhecida principalmente pela Romaria realizada na Rodovia dos Romeiros, localizada na GO-060, interligando as cidades de Goiânia-GO a Trindade-GO. O percurso da peregrinação compreende um total de 18 quilômetros de caminhada a pé, a qual passa a ser percorrida pelos diversos romeiros ao longo dos dez dias festivos. Nesse contexto, o caminho é composto de vários elementos, como barracas de apoio aos romeiros, comércios temporários, além de contemplar grandes painéis que simbolizam as estações da Via-Sacra, sendo estes pontos de paradas dos romeiros pintados pelo artista Omar Souto na representação da Paixão de Cristo, trabalho que consolidou a Rodovia dos Romeiros como a maior galeria a céu aberto do mundo (Jornal Opção, 2019; Túlio, 2019; Almeida, 2020).

A partir do exposto, tendo em vista reduzir a lacuna existente de pesquisas na área de estudos organizacionais sobre o fenômeno da peregrinação, este trabalho tem como objetivo compreender a peregrinação em honra ao Divino Pai Eterno em Trindade-Goiás a partir das percepções dos romeiros que realizam a caminhada, considerando quatro dimensões principais: identitária, religiosa, turística e econômica. 
A realização do estudo contribui para que a realidade da peregrinação e suas peculiaridades sejam compreendidas de forma mais profunda no âmbito científico, o que possibilita novas percepções sobre esse fenômeno religioso e instiga novas abordagens de análise no campo organizacional. De forma complementar, o estudo possibilitará conhecer os desafios da peregrinação analisada, colaborando para o desenvolvimento de políticas públicas direcionadas aos atores sociais que participam do ato religioso, estimulando transformações socioeconômicas que contribuam para a manutenção da tradição religiosa.

Este trabalho encontra-se estruturado em cinco sessões, incluindo a presente introdução. Na segunda sessão é apresentada a fundamentação teórica do estudo, a partir de conceitos sobre peregrinação e abordagem das quatro dimensões de análise da pesquisa, quais sejam: identitária, religiosa, turística e econômica. Na terceira sessão são apresentados os aspectos metodológicos adotados no estudo para a obtenção dos dados. Na quarta sessão são apresentados, e analisados, os resultados do estudo. Por fim, na quinta sessão do trabalho são apresentadas as considerações finais da pesquisa.

\section{FUNDAMENTAÇÃO TEÓRICA}

Ao buscar um entendimento acerca das peregrinações, diversas abordagens e estudos se apresentam como alternativa para aclarar esse conceito e explicar as peculiaridades dessas manifestações. Por sua vez, o estabelecimento de uma conceituação acerca dessa temática possibilita chegar a um entendimento de caráter análogo de diferentes áreas, como turística, geográfica e organizacional, sendo as peregrinações definidas enquanto manifestações que se revelam por meio da expressão da fé em devoção a uma divindade religiosa, constituindo, em essência, no ato de deslocar-se em busca de lugares considerados santos. Esse deslocamento apresenta a veneração como uma de suas características ritualísticas, seja pedindo ajuda à divindade ou agradecendo pelas preces alcançadas e sendo interpretado como uma viagem que o peregrino está disposto a realizar, tendo como objetivo principal a chegada ao lugar sagrado (Souza, 2018; Adam, 2018; Antunes, Barroco \& Dias, 2016; Cardita, 2012; Santos, 2000).

Para oferecer uma discussão acerca dos elementos inerentes ao fenômeno da peregrinação, inicialmente a temática será apresentada a partir de contribuições do campo de estudos do turismo. Assim posto, partindo dessa abordagem de análise, a ascensão das peregrinações no contexto do cristianismo é descrita como evento decorrente do expressivo surgimento de diversos santos, principalmente em decorrência da construção de novos centros de peregrinação. Outro elemento que corresponde ao incremento dessas jornadas devocionais baseia-se na ligação existente entre peregrinação e penitência apresentada pela Igreja católica, resultando na concepção da peregrinação enquanto forma de salvação dos pecados praticados pelos romeiros (Santos, 2000).

Entendidas como romarias coletivas, essas manifestações religiosas, além de terem como principal elemento as visitações aos lugares considerados santos, também englobam aspectos socioculturais. Essa realidade decorre, principalmente, por grande parte das festividades religiosas contemplarem a prática da peregrinação em devoção ao santo celebrado, vinculando o campo do sagrado ao contexto cultural. Em outras palavras, as peregrinações são comumente 
realizadas quando há a prática festiva em devoção a uma divindade, sendo uma forma de expressar a crença e a fé no santo celebrado (Rocha \& Belchior, 2016; Santos, 2000).

As peregrinações se constituem em elementos singulares, sendo um mecanismo impulsionador do turismo religioso local, refletindo a relação existente entre turismo e religião. Como defende Ribeiro (2003), a institucionalização do turismo religioso está diretamente relacionada à prática das peregrinações, pois, conforme as romarias foram sendo realizadas ao longo do tempo, consequentemente, os deslocamentos religiosos provocaram uma mudança gradativa nas paisagens, sendo estas modificadas para atender às novas necessidades dos romeiros. Nesse sentido, o aumento da oferta e a facilidade de serviços hoteleiros, alimentícios e de transportes nas hierópolis - cidades-santuários-, tornaram-se evidentes e expressivos, já que as cidades passaram a receber um grande fluxo de visitantes, principalmente em datas comemorativas aos santos padroeiros. Dentre alguns dos locais turísticos religiosos mais visitados podem ser destacados Meca, na Arábia Saudita; Jerusalém em Israel; Roma na Itália; e Santiago de Compostela na Espanha (Santos, 2000).

Analisando o cenário brasileiro, é possível dizer que as peregrinações ou romarias realizadas no país refletem um movimento turístico de amplo potencial, que oportuniza a união entre lazer e religião, ao mesmo tempo em que origina novos sentidos, renovando os ritos e as práticas religiosas de maneira contemporânea (Rocha \& Belchior, 2016).

O turismo religioso compreende uma gama de festividades relacionadas à religiosidade como missas, novenas, espetáculos, seminários, procissões, dentre outras atividades voltadas à evangelização. De forma complementar, o escopo do turismo religioso também promove a realização de atividades que se desvinculam da esfera religiosa/espiritual, podendo transcender ao consumismo, como a venda de artigos religiosos e a oferta de produtos de vestuário, equipamentos eletrônicos e produtos de utilidade doméstica, atividades que são impulsionadas, principalmente, a partir das festas religiosas em virtude das peregrinações (Almeida, 2020; Serra \& Tavares, 2016).

Por sua vez, as mudanças decorrentes do turismo religioso nas cidades-santuários são identificadas pelos novos postos de trabalho que surgem no mercado, o empreendedorismo e a criação de riquezas, a partir do desenvolvimento econômico local. É cada vez maior o interesse de turistas em vivenciar experiências que aliem o cultural com o espiritual e, nesse sentido, as peregrinações em cidades que praticam o turismo religioso possibilita aos romeiros vivenciar momentos de fé, ao mesmo tempo em que se oferta ampla diversidade de serviços e produtos autênticos, principalmente em se tratando de contextos festivos religiosos (Antunes, Barroco \& Dias, 2016).

Em complemento à compreensão dessa temática, ao adentrar às contribuições do campo geográfico para o entendimento das peregrinações, Souza (2018) expõe que a relevância em investigar o contexto da peregrinação faz sentido na medida em que as romarias possuem acepções geográficas, envolvendo uma dinâmica entre os mais variados espaços, sendo considerado o trajeto da peregrinação um lugar de devoção e dotado de simbologias e significados. Assim, o ato de peregrinar é entendido como a movimentação do homem no espaço e, nesse aspecto, 
O peregrino expressa valores e confiança nos espaços sagrados, o que pode ser verificado por meio dos seus comportamentos, de teor físico e simbólico. As dinâmicas dos espaços e tempos das peregrinações denotam manifestações de fé e devoções populares definidas social e culturalmente, comportando aproximações com dimensões da vida que ultrapassam 0 aspecto religioso (Souza, 2018, p. 687).

Cabe destacar que ambas as terminologias - peregrinação e romaria - possuem o mesmo sentido, referindo-se ao ato de peregrinar pela fé em busca dos lugares sagrados (Adam, 2018; Souza, 2018). Romaria decorre das peregrinações realizadas na cidade de Roma, considerada como um dos centros de visitações mais importantes do cristianismo e logo essa terminologia passou a designar toda e qualquer peregrinação, sendo utilizada nos dias atuais para fazer referência a qualquer tipo de manifestação religiosa que tenha como princípio o deslocamento de pessoas em devoção.

De forma complementar, nas menções de Almeida (2020), a caminhada realizada até - local de destinação está amparada na crença do romeiro à divindade e, por isso, o peregrino se dispõe a enfrentar as dificuldades encontradas no trajeto da peregrinação, como sol, chuva, dores no corpo e até mesmo os riscos e perigos a que o romeiro fica exposto durante o percurso. Dessa forma, é possível compreender que a peregrinação é um ato de entrega do indivíduo à vivência da religiosidade, manifestada em uma experiência única do homem.

O ato de peregrinar é caracterizado pelos espaços de início e chegada dos romeiros e os lugares que evidenciam o cumprimento da jornada correspondem ao santuário da religião devotada ou a um local de consagração. Nesse sentido, os santuários são descritos como destinos sagrados, sendo compostos por uma amplitude de histórias e culturas próprias, relacionando o contexto religioso de fé com a cultura dos indivíduos (Souza, 2018; Ribeiro, 2003).

Relacionando a peregrinação à conjuntura festiva religiosa, as contribuições dos estudos de Rosendahl e Corrêa (1999) apresentam compreensões que auxiliam no entendimento das implicações das romarias no contexto religioso. Conforme as festas religiosas acontecem, tais celebrações corroboram a criação de um cenário de oportunidades de mercado que impulsionam a comercialização e o consumo, seja na cidade ou no percurso da romaria, em especial de artigos religiosos, como a venda de terços, bíblias, imagens e demais produtos de natureza religiosa, consolidando as peregrinações como um dos principais elementos de manutenção do cenário econômico festivo (Rosendahl \& Corrêa, 1999).

Por sua vez, no tocante às abordagens sobre peregrinação a partir do campo da ciência da religião, as contribuições dos estudos possibilitam compreender a romaria como um rito, uma maneira de se apropriar dos sentidos, das simbologias e das crenças que constituem o campo religioso católico, popular e tradicional de determinada região. Por sua vez, em sua maioria, essa prática religiosa está associada ao cumprimento de uma promessa, no ato de pedir graças ou agradecer por aquelas recebidas, refletindo na lealdade estabelecida entre 0 romeiro e o santo de devoção (Steil, 1996). Assim, é possível compreender a romaria enquanto uma ação de entrega e transformação do indivíduo.

De todas essas significações é que se revestirá o ato voluntário da partida e da marcha para um alhures, um lugar diferente em que se realizará uma mudança de vida, que constitui a experiência da peregrinação: não um simples rito de 
devoção, mas um processo de transformação do ser em consequência de sua partida do meio e do gênero de vida habituais (Meslin, 1992, p. 152 apud Santos, 2005, p. 34-35).

Dessa forma, entende-se que o processo da peregrinação está associado a um estado de desacomodação do indivíduo, o qual, a partir da experiência fervorosa ao santo, é conduzido ao encontro do mistério, vivenciando experiências de crença, emoções e sacrifícios (Martins, 2001). Em adição ao exposto, os romeiros se deslocam de seus ambientes habituais por diferentes motivações, sendo, em maioria, voltadas à busca de curas de doenças físicas e espirituais. Nesse percurso, o trajeto e os elementos presentes nesse caminho corroboram para que o devoto se sinta como parte da romaria, refletindo diretamente na própria experiência de fé. Tal experiência é manifestada na ideia de que, ao ser romeiro, o indivíduo traduz comportamentos que exprimem a devoção, a caridade, o cumprimento à lei divina, sendo fiel aos princípios e valores pregados pela divindade religiosa. Nesse aspecto, ao se identificar com as vivências decorrentes do trajeto, o indivíduo passa a estabelecer uma profunda relação com o sagrado, sendo esta compreendida, principalmente, a partir de elementos que correspondem à religiosidade.

Essa manifestação religiosa engloba uma multiplicidade de significados que variam mediante a percepção e experiência de cada indivíduo que a pratica. Dessa forma, tornase imprescindível a interpretação dessa manifestação a partir de distintos significados, os quais envolvem tradições religiosas e as novas formas de significações que são atribuídas por seus praticantes, refletindo, inclusive, em processo de construção de identidade.

\section{...toda peregrinação cria e recria um campo ov espaço de educação, que media e veicula a experiência do tornar-se, do vir a ser no processo de desenvolvimento e construção da identidade social da pessoa (Steil \& Carneiro, 2008, p. 108).}

A partir do exposto, é possível inferir que a prática religiosa da peregrinação compreende aspectos que refletem identidade, corroborando para que o indivíduo se perceba enquanto romeiro conduzido pela fé e, nesse sentido, ao realizar a prática da peregrinação, o devoto tem a possibilidade de vivenciar um processo de imersão no sagrado (Braga, 2010).

Ao buscar um entendimento dessa temática no campo das Ciências Sociais, Aragão (2014) disserta que as peregrinações culminam em um fenômeno relacionado às vivências e crenças do homem, o qual busca, por meio da realização da romaria, vivenciar uma experiência com a divindade religiosa que ele acredita existir. Em outras palavras, a romaria é a significação da busca do homem pela procura de Deus, de entendimentos e auxílio às necessidades, sejam estas de caráter espiritual ou material. Steil (1996) aponta para o fato de que a romaria evidencia a pluralidade católica, envolvendo os romeiros em um conjunto de simbologias, valores e princípios, nos quais a relação existente entre o rito e a cultura está na apreensão do significado dos cultos realizados nos santuários. Para o autor:

As romarias são portadoras de uma tradição que é continuamente reinventada por romeiros, moradores e pelo clero, como uma forma de legitimar valores, ações, normas de comportamento. Quando evocam a tradição, esses diversos atores pretendem, na verdade, acionar um estoque de referências religiosas e práticas rituais que foram sendo acumuladas em torno do santuário, ... usadas para socializar seus sistemas de ideias e padrões de comportamento (Steil, 1996, p. 113). 
De forma complementar, Almeida, Enoque e Borges (2019) dissertam que as peregrinações correspondem a manifestações que expressam a devoção por meio do sacrifício da caminhada, sendo possível, em sua realização, o encontro de variadas culturas e gerações, e nesse aspecto, as festas religiosas são compreendidas como um acontecimento social, contribuindo para a reafirmação de uma tradição histórica. Em adição ao exposto, ao dissertar sobre as práticas ritualísticas intrínsecas à peregrinação, Aragão (2014) expõe sobre as festas religiosas, apontando que essas manifestações se constituem em elementos que intensificam e estimulam a prática da peregrinação, sendo entendidas como mecanismos de incremento ao turismo religioso. Nesse sentido, a medida em que essa manifestação religiosa - romaria é compreendida como um elemento propulsor do turismo religioso a partir da ocorrência das festas religiosas, a conjuntura econômica das localidades em que essas peregrinações são o locus de encontro entre o devoto e o destino sagrado passam a ser modificadas, oportunizando possiblidades de crescimento, a partir da ascensão do emprego e renda nas comunidades.

Em conformidade ao exposto e, visando maior compreensão desse contexto, tomemos como base os estudos de Almeida, Enoque e Borges (2019), que, ao realizarem uma investigação sobre festas populares religiosas no campo de estudos organizacionais, consideraram uma das dimensões apresentadas segundo o modelo proposto pela geógrafa Zeny Rosendahl para a compreensão de festas religiosas católicas: a dimensão econômica da religião, difundida em bens simbólicos e mercados (Almeida, Enoque \& Borges, 2019; Rosendahl \& Corrêa 1999). Os bens simbólicos, nesse aspecto, reluzem a produção capitalista mercantilista e englobam os produtos que possuem singularidades de religiosidade. Conforme as festas religiosas acontecem, tais celebrações corroboram na criação de um cenário de oportunidades de mercado que impulsionam a comercialização e o consumo, seja na cidade ou no percurso da romaria, em especial de artigos religiosos, como a venda de terços, bíblias, imagens e demais produtos de natureza religiosa, consolidando as peregrinações como um dos principais elementos de manutenção do cenário econômico festivo religioso (Rosendahl \& Corrêa 1999).

Em complemento ao exposto, as festas religiosas colaboram para a economia local de forma significativa, possibilitando o crescimento de vários setores no mercado. Hotéis, restaurantes e bares, supermercados e lojas podem ser descritos como alguns dos diversos ramos que são impactados pelo crescente número de visitantes e turistas nas cidadessantuários, refletindo no progresso econômico urbano. Além disso, cabe destacar que, em muitas dessas festividades, a montagem de barraquinhas na cidade, ou nos espaços da peregrinação, é vista como um dos principais elementos de representação dessas festividades católicas, ainda mesmo que tais comércios temporários não possuam relação com instituições religiosas (Enoque, Borges, Borges, Mariano Filho \& Dantas, 2013; Rosendahl, 2003). Assim posto, é possivel entender as peregrinações enquanto fator de expansão econômica dos lugares de celebrações, potencializando o mercado financeiro local e contribuindo com a atividade artesanal e turística de cada região.

De forma geral, a partir das discussões apresentadas, entende-se que a peregrinação, enquanto manifestação de fé, pode ser compreendida a partir de contribuições de diferentes campos de estudo. No entanto, destacam-se lacunas no campo 
de pesquisas organizacionais que explorem as peculiaridades intrínsecas à prática da peregrinação. A partir do exposto, as contribuições apresentadas acerca desse fenômeno religioso oferecem a possibilidade de investigação a partir de diferentes dimensões de análise, as quais configuram-se em quatro dimensões complementares: identitária, religiosa, turística e econômica. Analisar a peregrinação a partir do fator identitário respalda-se em aspectos que relacionam diretamente as peregrinações a elementos de religiosidade, e estes, por sua vez, tornam-se impossíveis de serem configurados, excluindo o aspecto turístico religioso que o circunda. Da mesma forma, as dimensões descritas anteriormente encontram-se associadas à dimensão econômica, já que o turismo religioso e a ascensão das festas religiosas representam, sobremaneira, as mudanças econômicas provocadas nas cidades-santuário, bem como evidenciam a importância das manifestações religiosas para o desenvolvimento local. Contudo, entende-se que as peregrinações, analisadas a partir das dimensões propostas neste estudo, tornam possível uma compreensão mais profunda dessa manifestação religiosa a partir das perspectivas daqueles que a realizam, ou seja, os romeiros, contribuindo de forma significativa no campo de estudos organizacionais.

\section{METODOLOGIA}

Este estudo, de natureza essencialmente qualitativa, utilizou entrevistas semiestruturadas como instrumentos para coleta dos dados. É importante dizer que as pesquisas qualitativas compreendem realidades múltiplas e subjetivas, valorizando as percepções e experiências do público analisado (Patias \& Von Hohendorff, 2019). Quanto à utilização de entrevistas semiestruturadas neste estudo, tal emprego decorreu da possibilidade de introduzir questões consideradas relevantes à investigação, visando tornar mais claros os argumentos apresentados pelos sujeitos de pesquisa acerca do assunto abordado (Boni \& Quaresma, 2005).

Assim posto, as entrevistas foram orientadas por um roteiro contendo perguntas previamente estabelecidas aplicadas no período entre junho e dezembro do ano de 2019. Por sua vez, a pesquisa compreendeu um total de 6 (seis) peregrinos participantes, os quais permitiram a gravação e a posterior transcrição das entrevistas para análise, conforme assinatura do Termo de Consentimento Livre e Esclarecido. No quadro abaixo, apresenta-se o perfil dos respondentes da pesquisa:

Quadro 1: Perfil dos respondentes

\begin{tabular}{|c|c|c|c|c|c|}
\hline \multicolumn{7}{|c|}{ Perfil dos respondentes (6 entrevistados) } \\
\hline Descrição & Sexo & Idade & Raça & Escolaridade & Religião \\
\hline Peregrino 1 & Masculino & 50 anos & Pardo & $\begin{array}{c}\text { Ensino Fundamental } \\
\text { incompleto }\end{array}$ & Católica \\
\hline Peregrino 2 & Feminino & 29 anos & Negra & Ensino Médio completo & Católica \\
\hline Peregrino 3 & Masculino & 52 anos & Pardo & Ensino Médio completo & Católica \\
\hline Peregrino 4 & Masculino & 25 anos & Negro & Ensino Médio completo & Católica \\
\hline Peregrino 5 & Masculino & 25 anos & Pardo & Ensino Médio completo & Católica \\
\hline Peregrino 6 & Feminino & 35 anos & Parda & Ensino Superior completo & Católica \\
\hline
\end{tabular}

Fonte: Elaborado pelos autores (2020). 
Destaca-se, ainda, que a quantidade de 6 (seis) entrevistados participantes é justificada pelas dificuldades encontradas no campo de pesquisa, considerando que os indivíduos foram abordados durante e ao final da jornada da peregrinação. Neste momento, eles demonstravam muito cansaço em decorrência da longa caminhada, sendo que, nestas circunstâncias, a realização das entrevistas configurou-se como tendo um caráter mais dificultado. Assim, o desenvolvimento das entrevistas ocorreu da seguinte forma: 1 (uma) entrevista realizada no mês do junho e 1 (uma) entrevista realizada no mês de julho, ambas contemplando o período festivo e aplicadas ao final da peregrinação. Por sua vez, apesar de todos os participantes do estudo terem sido abordados e convidados para a pesquisa durante e ao final da romaria, o aceite em participação dos outros 4 (quatro) participantes foi consentido, desde que as entrevistas ocorressem em momento posterior à festa. Dessa forma, 4 (quatro) entrevistas foram aplicadas nos meses posteriores (agosto, setembro, outubro, novembro e dezembro de 2019), sendo as entrevistas realizadas em locais públicos como praças, nas respectivas cidades de moradia dos entrevistados, contemplando as cidades de Ituiutaba-MG, Goiânia-GO e Trindade-GO.

Para a análise dos dados, optou-se pela técnica Análise de Discurso. Por sua vez, esse tipo de análise caracteriza-se por verificar o sentido produzido da mensagem que está sendo transmitida, e não o conteúdo do texto. Assim, considera-se o posicionamento do participante em relação às ideias que traduzem a representação do que está sendo investigado, ou seja, "a história representa o contexto sócio-histórico e a linguagem é a materialidade do texto gerando "pistas" do sentido que o sujeito pretende dar ... trazendo sentidos pré-construídos que são ecos da memória do dizer" (Caregnato \& Mutti, 2006, p. 680-681). Dessa forma, a análise de discurso baseia-se na premissa de que será feita uma nova interpretação, ou uma releitura, do que foi apresentado na mensagem, extinguindo a intenção de julgamento e sem a pretensão em afirmar o que é certo (Caregnato \& Mutti, 2006).

\section{RESULTADOS}

Este trabalho tem como objetivo principal compreender a peregrinação em honra ao Divino Pai Eterno em Trindade-Goiás (elemento componente do contexto festivo religioso praticado na cidade de Trindade/GO), a partir das percepções dos romeiros que realizam a caminhada, considerando quatro dimensões principais: identitária, religiosa, turística e econômica.

A Festa em devoção ao Divino Pai Ełerno engloba um rol de celebrações como missas campais, batizados, confissões, procissões, shows artísticos, novenas, orações de terços e exposições da cultura goiana (como a Romaria dos Carros de Boi, por exemplo), sendo um atrativo para fiéis, romeiros e turistas (Gonçalves, 2019a; Gonçalves, 2019b; O Popular, 2019; Tomazini, 2019). Apesar de compreender esta diversidade de celebrações, a Romaria realizada na Rodovia dos Romeiros pelos peregrinos é considerada como o marco da festividade religiosa, reunindo um número significativo de pessoas que fazem a caminhada ao longo dos dez dias de festa.

Quanto à abordagem turística em relação à festividade, é possível entender que a realização da referida festa contribui para que Trindade seja vista como destino turístico de Goiás, promovendo, assim, a cultura, o lazer e, principalmente, fomentando a economia regional, 
uma vez que vários setores como o alimentício, o hoteleiro, o de transportes e o comercial são impactados positivamente pelo aumento da demanda nesse respectivo período (Jornal Opção, 2019; Túlio, 2019).

A partir do exposto, e com o objetivo de analisar a peregrinação investigada nesse estudo, partiremos das percepções que o peregrino tem a respeito de sua própria condição identitária para, a seguir, abordar as dimensões religiosa, turística e econômica.

Nesse sentido, quanto à dimensão identitária, o enunciador do fragmento discursivo (001) menciona, explicitamente, os personagens do romeiro e de Deus. Há, adicionalmente, neste fragmento, a presença de dois aspectos ideológicos defendidos pelo enunciador deste discurso que contribuem para a compreensão da identidade do romeiro. O primeiro diz respeito à ideia de que o romeiro seria aquele indivíduo que cumpre as normas ("O romeiro tem de andar nas normas"). Vale destacar que para este enunciador as normas não são exatamente as leis mundanas, mas, sim, as leis de Deus ("Tem que ser as normas de Deus"). O segundo aspecto ideológico defendido estaria relacionado à ideia de que o romeiro seria um indivíduo que pratica a caridade ("O romeiro é aquele que abre o seu coração para o próximo"). Reforça tal ideia o fato de que o enunciador, ao qualificar o romeiro como um praticante da caridade, utiliza-se de uma metáfora recorrente na linguagem coloquial brasileira, qual seja, a do "coração aberto".

(001) Ah, o romeiro, prá mim, tem que ter o coração aberto, tem que ser bão né? O romeiro tem que andar nas normas que têm que ser as norma de Deus né? Porque tem muito romeiro que fala que é romeiro mas não tem o coração aberto (...) Ali na hora ele é uma coisa e depois ele é outra. Então, eu acho que o romeiro é aquele que abre o seu coração pro próximo (Entrevistado 01).

Um outro elemento importante destacado pelas seleções lexicais dos fragmentos discursivos (002) e (003) é a temática da fé. Para os enunciadores dos fragmentos supracitados, o romeiro seria aquele indivíduo que caminha por causa de sua fé ("O romeiro é aquele que caminha por causa da sua fé") e que ela (a fé) o diferenciaria, de um certo modo, de um fiel comum, com características ordinárias ("É um fiel que tem muita fé"). Nota-se, neste ponto, o caráter devocional desta caminhada como uma ação de cumprimento de um voto (pagamento ou agradecimento por uma cura, por exemplo) ou de um pedido (fragmento 005). Esta peregrinação, de caráter ritualístico, fortemente influenciada pelas tradições católica e familiar (fragmentos discursivos 004 e 006), interromperia, para os seus participantes, no ano, uma temporalidade ordinária/comum e instauraria, em seu lugar e no período da festa, um tempo especial (sagrado). Assim, a festa do Divino Pai Eterno em Trindade/GO parece representar a emergência, tanto de uma temporalidade, quanto de uma espacialidade de natureza sagrada.

(002) O romeiro é aquele que caminha por causa da sua fé. (Entrevistado 02)

(003) Uai, prá mim [peregrino] é um fiel que tem muita fé, que vai (...) em busca, aos pés do santo que você tem muita fé. (Entrevistado 03)

(004) Ah, o romeiro eu falo assim, que é aquele pessoal de todo ano ocê ir. A gente vai todo ano, minha mãe, meu pai, às vezes meu irmão. Agora ele sofreu acidente e não dá prá ele ir mais, mas todo ano eu vou. Desde os 8 anos eu sou romeiro. (Entrevistado 04)

(005) Ah, o peregrino prá mim é (...) as pessoas que muitas vezes que têm algum voto a cumprir, e vai todo ano, e faz a caminhada tipo como se fosse um cumprimento do voto, uma devoção ao santo. (Entrevistado 05) 
(006) Tem 20 anos que a gente faz essa caminhada. (...) Já veio de família, né? A tradição (...) de pai, de mãe (...) Era devota, já fazia as caminhada. Antigamente as caminhada saía daqui, né? Só que agora não tem aqueles apoio igualzinho a gente tem lá emTrindade. Graças a Deus o apoio de Trindade é muito bão (Entrevistado 01).

Conforme pode ser observado nas seleções lexicais dos fragmentos discursivos (007), (008), (009), (010) e (011), os motivos pelos quais os peregrinos realizam a caminhada estão normalmente relacionados a questões ligadas à saúde ("As minhas vistas, né, era ruim demais. Eu não tava enxergando quase nada"; "Outra graça que eu recebi do Divino Pai Eterno foi que eu tinha uma pedra nos rins"; "Quando eu era criança, minha mãe disse que eu era muito doente"); bem como a acidentes ("Depois que eu sofri o acidente, a gente pega muito na força de (Deus)"); ou, até mesmo a aspectos econômicos como o desemprego, por exemplo (fragmento (011)).

No que diz respeito às questões ligadas à saúde (como elementos motivadores da realização da peregrinação), alguns elementos importantes devem ser observados. O primeiro é o de que a peregrinação se apresenta como uma forma de agradecimento por parte do fiel (ou de algum membro de sua família), por alguma cura recebida ou, até mesmo, por um pedido de que a sua doença cesse. É recorrente, neste aspecto, que os fragmentos discursivos (007), (008) e (009) apresentem-se como tendo uma natureza fortemente testemunhal. O enunciador do fragmento discursivo (007), por exemplo, relata uma doença ocular preexistente (aparentemente catarata) que o impedia de ver claramente. Tomado pela fé e a espera de uma benção, o enunciador afirma utilizar-se da oração e da água (esta última compreendida, mesmo que metaforicamente, como um elemento que limpa, lava, purifica) como forma de cura. É importante destacar, neste fragmento, a possibilidade de compreender uma certa associação entre o "abrir os olhos para ver o mundo" e o "abrir os olhos para a fé, para Deus". Da mesma forma, a utilização da expressão "lavar a alma" apresenta a peregrinação como tendo um caráter de purificação do corpo e da alma (fragmento 012).

O mesmo parece ocorrer no fragmento discursivo (008), no qual o enunciador apresenta um problema renal (pedra nos rins), aparentemente curado e "pago" através da peregrinação. Da mesma forma dita anteriormente, seria interessante compreender, neste fragmento, a pedra no rim como uma metáfora da pedra que se apresenta no meio do caminho do peregrino.

(007) (...) o que me leva é porque a gente já recebeu várias bênçãos, desde a época da minha família, do meu pai e da minha mãe; recebeu muitas bênçãos, inclusive eu mesmo tive um milagre muito grande: as minhas vistas, né, era ruim demais, eu não tava enxergando quase nada e eu passei seguir a novena igualzinho cê tá vendo aqui. Todo dia tá ligado no Divino Pai Ełerno, eu comecei a pôr a água nos olhos. Depois de quando eu comecei a pôr a água nos olhos, nunca mais minhas vistas escureceram. Minhas vistas é boa hoje. Foi uma benção que eu recebi (Entrevistado 01).

(008) E a outra graça que eu recebi do Divino Pai Ełerno foi que eu tinha uma pedra nos rins e tinha feito uma consulta com o médico e ele falou assim: "Olha, você vai ter que operar na sexta-feira." "Olha sexta-feira agora não vai ter jeito de eu operar não que eu tô indo prá Trindade". "Então vai operar na terça-feira; na terça-feira você vai ser operado." Já tinha tirado chapa, tirado tudo. Aí eu fui na caminhada, pedi muito o Divino Pai Eterno porque eu tenho muito medo de ser operado, tenho muito medo de faca. Até hoje eu nunca fui operado. Pedi 
muito o Divino Pai Eterno que Ele aliviasse, tirasse essa pedra de mim e aí fomos na caminhada, rezei, agradeci, pedi muito a Ele, fui na sala de promessa, fui na igreja velha, na igreja nova e aí a gente foi embora. Cheguei aqui. Quando foi na terçafeira eu fui. Aí levei um papel que nem esse aqui ôh, que era o papel que tava constando tudo. Aí na hora que ele [médico] olhou o papel não tinha nada. A aí ele falou assim: "cê vai (...) tirar outro exame". Aí foi, tirou. Levei o papel. Ele olhou e: "Não tem nada", "Uai, mas tinha aqui, nós ia operar". Aí fomos no hospital São José de novo prá tirar a dúvida porque ele não tava acreditando. Aí ele olhou de novo (...) e falou: "Ôh, eu não vou te operar porque realmente não tem nada aqui nos papel que você tinha. O que que você fez?" (...) Falei: nada. Que as pessoa, os médico não acredita né? Aí hora que eu cheguei em casa e bati o joelho no chão, acreditei mesmo e falei: "De agora prá frente enquanto eu tiver vida eu vou fazer então essa caminhada; enquanto eu tiver vida, tiver aguentando andar, caminhar, eu sou romeiro do Divino Pai Eterno" (Entrevistado 01).

(009) Quando eu era criança minha mãe disse que eu era muito doente e aí ela fez um voto de deixar meu cabelo crescer até os 7 anos, inclusive meu cabelo era grande, e cortar e levar uma foto vestido de anjo (...) nos pés do Divino Pai Eterno e aí a gente foi e fez isso. E aí, depois disso, depois que eu sofri o acidente, esses amigo meu de Goiânia são muito devoto e aí eles propôs: nóis vamos te levar todo ano empurrando a cadeira (Entrevistado 03).

Em relação a questões ligadas a acidentes ou de natureza econômica (desemprego), ou mesmo prática (necessidade de passar em uma prova, por exemplo), os motivos de realização da peregrinação revelam, também, elementos bastante interessantes. De acordo com o enunciador do fragmento discursivo (011), a peregrinação cumpriria uma função de "resolver" uma situação econômica desfavorável (desemprego) vivida pelo entrevistado. Note que o enunciador caracteriza, assim, o conseguir o emprego como sendo algo de caráter miraculoso, divino (distante de sua formação, habilidades e competências).

(010) Uai, hoje, (...) depois que eu sofri o acidente a gente pega muito na força de (...) pedir que as coisas dê certo, então esse é um motivo. A gente pede com muita fé prá receber alguma coisa" (Entrevistado 03).

(011) Eu tive milagre. Eu tava desempregado e pedi: "Ôh Divino Pai Eterno, se eu conseguir o meu serviço, eu vou a pé todo ano que eu tiver vida, eu vou a pé prá Trindade, e fui" (Entrevistado 04).

(012) É a fé [que motiva], a fé, (...) parece que cê chega lá assim, de alma lavada, né?" (Entrevistado 06).

Esta realidade nos leva a compreender a caminhada como sendo uma espécie de "moeda de troca" em um mercado de bens simbólicos (passível, inclusive, de ser barganhada). Ela (a peregrinação) "pagaria" pela cura (dos próprios peregrinos ou de entes queridos), mas, também, por elementos mais mundanos como conseguir emprego ou passar em uma prova etc. É interessante, neste sentido, e conforme pode ser visto na seleção lexical do fragmento discursivo (013), a utilização do termo "pagar" por parte do enunciador. A utilização de tal verbo parece estar relacionada a uma certa "invasão" de um vocábulo do campo econômico (essencialmente capitalista) no campo religioso. Esta "barganha", além disso, parece aproximar o catolicismo de outras religiões cujo atendimento a demandas mundanas é mais recorrente e costumeiro como, por exemplo, em algumas igrejas neopentecostais.

(013) A hora que chega. (...) Não tem igual porque cê já agradece já; cê desce lá e já fala: Agora eu paguei! Consegui chegar" (Entrevistado 04). 
O fato é que esta "dívida de natureza espiritual" que, em alguns casos, parece alongar-se ao longo de vários anos como uma espécie de "financiamento", aliado ao aspecto devocional, faz com que o peregrino assuma um compromisso de realizar, periodicamente (anualmente), esta caminhada (fragmento 008). Conforme pode ser observado nas seleções lexicais dos fragmentos discursivos (014), (015), (016), (017) e (018), o caminho da peregrinação é considerado, pelos entrevistados como sendo sagrado ou santo. Haveria, neste sentido, uma certa "delimitação" entre o percurso da estrada percorrido pelos fiés (considerado como espaço do sagrado) e o entorno povoado de comerciantes e ambulantes (espaço do profano, do econômico). É dentro desta perspectiva que o enunciador do fragmento discursivo (018) revela certo incômodo com a venda e/ou o consumo de bebidas alcóolicas no decorrer do percurso. Esta intromissão do campo econômico no universo religioso ou, dito de outra forma, do mundano sobre o sagrado, parece reforçar, ainda mais, o caráter devocional da caminhada.

(014) Sim, um caminho sagrado, considero. Ôh, vou (...) falar a verdade prá você, não tem coisa melhor (...) se você tiver algum problema, qualquer coisa na sua vida, alguma dificuldade prá estudar, prá escrever, (...) alguma prova que você quer passar, você pega e faz a intenção que você vai descer e faz na intenção, entendeu? Mas você passa em todas as Via Sacra e reza prá aquilo que você quer. Te garanto que no próximo ano você vai tá realizada dos seus problemas (Entrevistado 01).

(015) Considero [O percurso como algo sagrado] (...), é muita emoção, sabe assim, é muita gente reunida na mesma fé (Entrevistado 02).

(016) Com certeza. [O percurso é sagrado] Porque você vai em busca da fé (...) então seu pensamento tá focado só no Divino Pai Eterno (...) até as conversa da gente é sobre isso (Entrevistado 03).

(017) Ali é [um caminho sagrado] (...) Não só porque assim eu recebi milagres, mas cê vê quando a gente termina de fazer aquela caminhada, que cê chega na igreja parece que ocê deixou um peso que tava com ocê todim, cê volta, cê tem cada realização que ocê fica bobo de vê (Entrevistado 04).

(018) (...) [O percurso] é um lugar santo, a pessoa tá ali às vezes prá pagar uma promessa, alguma coisa que ela fez, não precisa ter bebida alcoólica, uma água, um refrigerante, tudo bem, um suco, mas bebida alcoólica não precisa. Depois que ocê paga a sua coisa pode; o rapaz quiser bebida, bebe, mas antes ali naquela caminhada ali (...) lugar santo [não deveria] (Entrevistado 04).

(019) Eu, se eu tivesse uma força, eu não aceitaria ali naquele caminho da caminhada [a comercialização de bebidas alcóolicas], porque ali é uma caminhada sagrada de Deus (...), então uma pessoa que começa a beber ali vai caçar problema mais prá frente. Eu acho que ali naquela região da caminhada, não importaria suco, coca, refrigerante, cachorro-quente, até almoço tem; mas esse tipo de bebida não poderia vender; ali não (Entrevistado 01).

É importante destacar que o enunciador do fragmento discursivo (020) relata o mesmo incômodo do comércio e, porque não dizer, do profano no universo da festa em si. Para ele é como se o econômico insistisse e forçasse a venda de seus produtos e serviços, abalando uma temporalidade e espacialidade sagradas («Aquele pessoal que fica ali em cima forçando prá vender", "insistindo demais, muito mesmo"). Além disso, o que parece ocorrer, também seria uma certa "economia da mendicância" que perpassa não somente o caminho, mas, também, a festa (fragmento 020).

(020) Olha, lá tem muitas coisa que é coisa de Deus, mas tem muitas pessoa que tá ali pedindo esmola que não precisa, tem pessoas ali que é fazendeiro, tem pessoa ali (...) que põe uma carne viva e põe na perna prá pessoa pensar 
que tá machucada (...) eu acho que é pecado. Aquela pessoa que precisa de ser ajudada, tudo bem, porque tem pessoa ali que precisa, que tá com as duas perna cortada, pessoa que não tem braço, essas pessoas precisa, eu ajudo direto. Mas tem uns que não precisa ser ajudado, vê que não merece, entendeu? (Entrevistado 01).

Tal realidade faz com que a festa (e, por adição, a peregrinação), seja palco de, pelo menos, dois tipos de frequentadores, quais sejam: aqueles que vão só pela festa mesmo (denominados pelos entrevistados como sendo "turistas"); e aqueles que realmente consideram-se fiéis (que fazem o percurso e participam das liturgias religiosas). Nota-se, neste ponto, que alguns dos peregrinos passam a considerar a caminhada como sendo algo até mais sagrado do que a própria festa em si. O enunciador do fragmento discursivo (022), por exemplo, admite que realiza a peregrinação, participa das missas, mas não da festa ("A festa (...) eu nunca fiquei na festa").

(021) Aquele comércio, né, aquele comércio ali eu acho muito profano. (...) Acho que não tinha necessidade daquele tanto de barraca, aquele pessoal que fica ali em cima forçando prá vender. (...) nossa, insistindo demais, muito mesmo. (...) eu sei de pessoas que vai só pela festa mesmo, prá passear, nem vai na igreja, só pela festa mesmo" (Entrevistado 02).

(022) A festa (...) eu nunca fiquei na festa porque o tumulto é grande demais e eu não gosto de tumulto, mas é uma realização daquele ano que foi feito. Eu imagino assim, que foi cumprido naquele ano. (...) Das missas [participamos] sim (...) Uma missa só, na hora que nóis chega se tiver perto; a gente fica, se tiver longe; às vezes a gente volta no outro dia prá assistir à missa (Entrevistado 03).

(023) Ah, o peregrino é o cara que tá caçando a sua bênção e o turista, tem uns que tá caçando a sua bênção e tem uns que vai só prá divertir, prá ir pra forró (...) Prá curtição, entendeu? Tem muita diferença (...) cê pode ver que a pessoa que vai prá rezar é diferente (...) a missa da aurora, cê pode contar quantas pessoas que vai prá ir prá reza, outros que não vai tá tudo bêbado, cê entendeu? (Entrevistado 01).

Um elemento importante que reforçaria a percepção acerca da sacralidade da peregrinação está relacionado à existência, no percurso, de "estações/paradas" que são associadas, pelos entrevistados, à via-crucis de Jesus Cristo até o calvário. Conforme pode ser visto nas seleções lexicais dos fragmentos discursivos (024) e (025), os pontos de parada (estações da via sacra) não são somente utilizados para o descanso do corpo físico dos peregrinos. Estes pontos aparecem, além disto, como que carregados, nos discursos dos entrevistados, de um forte simbolismo religioso e de extremo caráter emocional. Seriam, fundamentalmente, paradas destinadas à reflexão acerca do sofrimento e do sacrifício de Jesus.

(024) Ah ali [Via Sacra] representa muito (...) ali cada pontinho é um sacrifício, cada pontinho você deixou um sacrifício prá trás porque a hora que ocê chega ali parece que dá até um pouco aliviado e ocê consegue ir mais além prá topar com a outra saída lá na frente (Entrevistado 04).

(026) (...) tem as paradas né, da cruz onde Jesus caminhou... a Via Sacra. (...) em cada parada dessa a gente (...) vai lá, acende uma vela cada um de nós, e (...) pede nossos votos, faz nossos votos lá e dali a gente segue em diante até a próxima parada. (...) geralmente a gente fica por volta duns 15 minutos, 20 minutos, até mesmo prá gente dar uma descansada um pouquinho. (...) [a Via-Sacra] representa o momento ali em que Jesus (...) sofreu muito né? Então cabe a cada um de nós, cada parada daquela a gente parar, e imaginar, né, como que foi, né, toda aquela cena. A gente para, reflete e, a partir daí a gente pede nossos votos, faz as nossas votações, e depois a gente segue em diante (Entrevistado 05). 
Este sofrimento ritualizado pela peregrinação é, nas palavras dos entrevistados, um dos principais desafios da caminhada (fragmentos (027) e (028). Conforme pode ser visto na seleção lexical do fragmento (027), o sacrifício parece ser, na perspectiva do enunciador, necessário para o alcance da fé ("Deus tem que mostrar que ele tem que passar por aquele sacrifício"; "A fé supera qualquer dor»).

(027) (...) Tá doendo, tá tudo. Quando eu comecei eu achei que eu não conseguia, as pernas começou travar, começou dar câimbra, e eu fui rezando e pedindo a fé, e a fé supera qualquer dor, se ocê tiver fé (...) mas se ocê começar a sentir uma dorzinha na perna e falar assim: "Eu não, vou parar que eu não dou conta". Pessoa nossa chegou com os pé tudo cheio de calo e sangue lá, mas conseguiu, não desistiu, cê entendeu!? Nos próximos anos não deu calo, não deu nada mais, quer dizer ele tinha que passar por aquele sacrifício, cê entendeu? Talvez a pessoa começa a perna doer e tal, mas Deus tem que mostrar que ele tem que passar por aquele sacrifício (...) (Entrevistado 01).

(028) Quando eu chego em Trindade geralmente eu chego com minhas pernas doendo um pouco. Meus pé também chega doendo. Aí na hora que o corpo descansa mesmo, que eu sento, por exemplo, eu sento lá um pouco e eu vou levantar depois. Nossa, aí as perna fica doendo, os pé doendo (...) sinceramente, eu quase não dou conta de andar! Mas aí como lá depois já é tudo pertinho, aí acaba que a gente consegue finalizar. (...) eu fico mais ou menos uns quatro dias com os pé doendo, as pernas doendo, de tanto ficar em pé e de tanto andar, né? (Entrevistado 05).

(029) A gente já começa já a se preparar bem antes, né? Porque, por conta de ser uns dois dias, né, tem que organizar comida (...) então a gente já começa bem antes. (...) Sim [faz uma preparação espiritual], a gente reza o terço no caminho até chegar em Goiânia (Entrevistado 02).

(030) Cada um faz um estilo de promessa. Tem muita gente que vai com terço, (...) aconteceu esse ano comigo. Eu vi um rapaz levando uma cruz grandona, então cada um faz um estilo de promessa e cada um, assim, que consegue chegar onde quer chegar, (...) ano passado teve uma mulher que era da Bahia. Ela pôs uma santa em cima da cabeça, eu lembro certinho, e foi daqui até lá sem cair e eu fiquei obcecado naquilo. (...) Sem ficar segurando, normal e ela caminhando com a santa na cabeça e eu fiquei com esse trem na cabeça. E esse ano foi com o rapaz da cruz; levou uma cruz grandona segurando na mão do filho dele e foi daqui lá com a cruz (Entrevistado 04).

Nesse sentido, faz-se necessária uma certa preparação, por parte do peregrino, não somente física (cuidados com a alimentação, hidratação, etc), mas, também, espiritual (fragmento (029). São constantes, neste contexto, relatos de peregrinos que realizam orações antes e durante o percurso, além de carregarem imagens, terços e, até mesmo objetos que representam doenças ou curas (pernas de madeira, por exemplo).

(031) O peregrino vai em busca da fé e o turista vai prá passear, né, aproveitar (Entrevistado 03).

(032) Prá mim (...) o peregrino ele vai com uma intenção né (...) a intenção em fazer a caminhada da fé e assistir todas (...) missas (...). Agora o turista geralmente ele vai mais prá conhecer, prá ficar andando, prá ver as coisas diferentes do que ele tá acostumado a ver. Então esse aí é o ponto de vista que eu vejo da diferença entre os dois (Entrevistado 05).

Podemos observar, por fim, nos fragmentos discursivos (031) e (032), uma clara delimitação representacional entre os universos do turista e do peregrino. O ser turista, na perspectiva dos enunciadores, estaria associado ao "passear" ("O turista vai para passear"), ao caminhar despretensioso e sem intencionalidade aparente ("Agora, o turista geralmente ele vai mais para conhecer, prá ficar andando, para ver as coisas diferentes do que ele tá acostumado 
a ver"). Nota-se, a partir disso, que a peregrinação se apresenta, em contrapartida, como uma forma de turismo intencionado pela fé ("O peregrino vai em busca da fé", "O peregrino ele vai com uma intenção né? (...) a intenção em fazer a caminhada da fé"). Esta realidade apresenta, na visão dos enunciadores, uma representação do turismo (e, por consequência, do turista) como sendo de natureza essencialmente negativa, ordinária, e, porque não dizer, mundana. Há, assim, implicitamente, a ideia de que o peregrino se coloca em um patamar moral religioso superior em relação aos demais participantes da caminhada.

\section{CONSIDERAÇÕES FINAIS}

Este trabalho teve como objetivo compreender a peregrinação em honra ao Divino Pai Ełerno em Trindade-Goiás, a partir das percepções dos romeiros que realizam a caminhada, considerando quatro dimensões principais: identitária, religiosa, turística e econômica.

Pôde-se observar, a partir dos dados analisados, que a peregrinação se apresenta, fundamentalmente, como sendo um ritual marcado pelo sacrifício e pelo sofrimento daquele que empreende esta caminhada. Este, o romeiro, motivado pela fé ou pela tradição familiar, empreende esta caminhada com o objetivo de cumprir os votos pedidos, ou concedidos, sejam eles de natureza econômica ou até mesmo relacionados a doenças ou de conteúdo mais cotidiano. Haveria, por assim dizer, uma certa barganha por parte do peregrino neste mercado de bens simbólicos instaurado não somente pela caminhada, mas, também, pela festa em honra ao Divino Pai Ełerno em Trindade/GO. Considerando o trajeto percorrido como sendo de natureza sagrada, o peregrino revela certo incômodo com a influência do campo econômico (comércio de bebidas e de outros produtos) na esfera religiosa e tende a separar as espacialidades e temporalidades, profanas e sagradas, tanto no universo da festa quanto da caminhada. Nesta mesma perspectiva, o peregrino tende a estabelecer diferenças entre "verdadeiros" e "falsos" fiéis (aqueles que frequentam simplesmente a festa em relação àqueles que realizam a peregrinação e participam das atividades religiosas), estabelecendo uma certa "hierarquia da fé". Em complemento, os peregrinos consideram-se como aqueles que, plenos de sua fé, cumprem as normas religiosas e pregam a caridade.

A realização do estudo possibilitou compreender, a partir da análise das quatro dimensões apresentadas na pesquisa (identitária, religiosa, turística e econômica), a relação e a contribuição dos resultantes ao campo de estudos organizacionais. As concepções dos espaços sagrados e profanos por parte dos peregrinos permite entender que tais espaços são possíveis de serem associados a outros tipos de organizações. De acordo com os resultados do estudo, à medida em que os peregrinos consideram o trajeto como um caminho munido de sacralidade, a atuação de determinados comércios naquele espaço colabora para que este público considere a venda de determinados produtos como uma atitude profana, principalmente no tange à comercialização de bebidas alcóolicas. Assim, de certa forma, é possível fazer uma associação desse contexto com outros tipos de organizações, em que os espaços de trabalho como, por exemplo, as salas da alta gerência, se tornam espaços sagrados, sendo proibidas determinadas ações por parte de todos os membros. Por sua vez, o elemento turístico e sua relação com o campo econômico permite identificar peculiaridades relacionadas ao fator mercadológico. A atuação dos pequenos negócios durante o período festivo, com destaque para a atuação 
de vendedores ambulantes, evidencia aspectos que remetem à realidade organizacional experimentada por empresas de diferentes ramos de atuação. Tais elementos podem ser apontados como o desafio para se manter no mercado e, principalmente, a forte relação de concorrência. No que diz respeito às limitações deste estudo, destaca-se o fato de que ele foi realizado sob a perspectiva de uma peregrinação específica (inserida em uma festa religiosa católica do estado de Goiás), não podendo estender seus resultados para outras manifestações culturais similares ou de outras religiões. Como possibilidades de estudos futuros, destacamos a necessidade de ampliarmos o escopo da pesquisa para outros atores também participantes da peregrinação como, por exemplo, comerciantes, poder público, igreja, entre outros.

\section{AGRADECIMENTOS}

Agradecimentos ao CNPq (Conselho Nacional de Desenvolvimento Científico e Tecnológico) pelo apoio e incentivo na realização de pesquisas científicas, e à CAPES (Coordenação de Aperfeiçoamento de Pessoal de Nível Superior), pela concessão da bolsa de estudos durante o curso de mestrado, contribuindo de sobremaneira no desenvolvimento da presente pesquisa.

\section{REFERÊNCIAS}

Adam, J. C. (2018). Entre peregrinação, turismo e liminaridade: a busca por lugares. Horizonte, 16(49), 66-87. doi: 10.5752/P.2175-5841.2018v16n49p66-87.

Almeida, L. L. S., Enoque, A. G. \& Borges, A. F. (2019). Empreendedorismo de Festas Populares: uma análise do modelo de dimensões proposto por Zeny Rosendahl para o estudo de festas religiosas católicas. Teoria e Prática em Administração, 9(2), 1-13. doi. 10.21714/2238-104X2019v9i2-42107.

Almeida, L. L. S. (2020). "Daí prá cá é meuı: territorialidades no contexto da Festa do Divino Pai Ełerno em Trindade-GO. Dissertação de Mestrado, Curso de Geografia, Instituto de Ciências Humanas do Pontal, Universidade Federal de Uberlândia, Ituiutaba. doi: 10.14393/ufu.di.2020.417.

Antunes, J., Barroco, C. \& Dias, H. (2016). A importância do turismo religioso no desenvolvimento das regiões: o caso do santuário da Nossa Senhora da Lapa. International Journal of Scientific Managment Tourism, 2(1), 273-285.

Aragão, I. R. (2014). Reflexões acerca do turismo cultural-religioso e festa católica no Brasil. Revista Grifos, 36(37), 53-67.

Bakhtin, M. (2006). Marxismo e filosofia da linguagem. São Paulo: Hucitec.

Boni, V. \& Quaresma, S. J. (2005). Aprendendo a entrevistar: como fazerentrevistas em Ciências Sociais.Em Tese: Revista Eletrônica dos Pós-Graduandos em Sociologia Política da UFSC, 2(1), 68-80. Recuperado de:https://periodicos.ufsc.br/index.php/emtese/article/viewFile/18027/16976+\&cd=1\&hl=ptBR\&ct=clnk\&gl=br. Acesso em: 21/05/2019.

Bourdieu, P. (2005). A economia das trocas simbólicas. São Paulo: Perspectiva. 
Braga, A. M. C. (2010). Devoção, lazer e turismo nas romarias de Juazeiro do Norte, CE: reconfigurações romeiras dos significados das romarias a partir de tensões entre as categorias turismo e devoção. PLURA: Revista de Estudos da Religião, 1(1), 149-161.

Calvelli, H. G. (2006). A "Santiago de Compostela" brasileira: religião, turismo e consumo na peregrinação pelo caminho da fé. Tese de Doutorado, Curso de Ciência da Religião, Instituto de Ciências Humanas, Universidade Federal de Juiz de Fora, Juiz de Fora.

Cardita, A. (2012). Peregrinação: possibilidades de compreensão crítica de uma experiência. Sociologia: Revista da Faculdade de Letras da Universidade do Porto, 24, 195-213.

Caregnato, R. C. A. \& Mutti, R. (2006). Pesquisa qualitativa: análise de discurso versus análise de conteúdo. Texto \& Contexto Enfermagem, 15(4), 679-684.

Coelho, T. O. (2021). Festa do Divino Pai Ełerno. IESA/UFG - Festas Populares. Recuperado de: https:// festaspopulares.iesa.ufg.br/n/3736-festa-do-divino-pai-eterno. Acesso em: 22/04/2021.

Enoque, A. G., Borges, A. F., Borges, J. F., Mariano Filho, V. P. \& Dantas, P. (2013). "A César o que é de César e a Deus o que é de Deus": Representações Sociais do Lucro na Perspectiva de Empresários do Ramo de Artigos Religiosos da Região do Triângulo Mineiro. In. Anais, XXXVII Encontro da ANPAD. Recuperado a partir de http://www.anpad.org.br/admin/pdf/2013_EnANPAD_EOR1230.pdf.

Gonçalves, R. (2019a, 03 de julho). Festa do Divino Pai Ełerno recebe sacerdotes de vários estados para atender romeiros. G1 Globo. Recuperado de: https://gl.globo.com/go/goias/noticia/2019/07/03/ festa-do-divino-pai-eterno-recebe-sacerdotes-de-varios-estados-para-atender-romeiros.ghtml. Acesso em: 20/02/2020.

Gonçalves, R. (2019b, 06 de julho). Procissão Luminosa e missas campais encerram a Festa do Divino Pai Eterno neste domingo. Gl Globo. Recuperado de: https://gl.globo.com/go/goias/ noticia/2019/07/06/procissao-luminosa-e-missas-campais-encerram-a-festa-do-divino-pai-eternoneste-domingo.ghtml. Acesso em: 20/02/2020.

Jornal Opção. (2019, 01 de julho). Festa do Divino Pai Ełerno, em Trindade, conta com shows sertanejos. Jornal Opção. Recuperado de: https://noticias.r7.com/jornal-opcao/festa-do-divino-pai-eternoem-trindade-conta-com-shows-sertanejos-01072019. Acesso em: 20/02/2020.

Marques, L. M. (2017). A peregrinação ao sagrado: os caminhos que levam à Romaria/MG. Tese de Doutorado, Curso de Geografia, Universidade Federal de Uberlândia, Uberlândia.

Martins, J. O. (2001). Os peregrinos do Divino Pai Eterno: os carreiros e a reprodução social da tradição. Dissertação de Mestrado, Curso de Ciências da Religião, Pontifícia Universidade Católica de Goiás, Goiânia.

Meslin, M. (1992). A experiência humana do divino. Petrópolis: Vozes. In Santos, J. Z. (2005). Romaria de Nossa Senhora da Água Suja. Dissertação de Mestrado, Curso de Ciências da Religião, Departamento de Filosofia e Teologia, Universidade Católica de Goiás, Goiânia.

O Popular. (2019, 08 de julho). Festa do Divino Pai Eterno, em Trindade, recebeu mais de 3 milhões de visitantes em 2019. Jornal O Popular. Recuperado de: https://www.opopular.com.br/noticias/ cidades/festa-do-divino-pai-eterno-em-trindade-recebeu-mais-de-3-milh\%C3\%B5es-de-visitantesem-2019-1.1837650. Acesso em: 20/02/2020.

Patias, N. D. \& Von Hohendorff, J. (2019). Critérios de qualidade para artigos de pesquisa qualitativa. Psicologia em Estudo, 24, 1-14. doi: 10.4025/psicolestud.v24i0.43536. 
Ribeiro, H. (2003). Andar com fé e o sentido do chegar. Caderno Virtual de Turismo, 3(1), 1-7.

Rocha, T. V. C. \& Belchior, M. H. C. S. (2016). A Intersecção entre peregrino e turista religioso: os diferentes caminhos ao sagrado. Revista Turismo em Análise, 27(2), 274-298. doi: 10.1 1606/issn.19844867.v27i2p274-298.

Rosendahl, Z. (2003). Espaço, cultura e religião: dimensões de análise. In R. L. Corrêa, \& Z. Rosendahl (Orgs.), Introdução à Geografia Cultural (pp. 187-224). Rio de Janeiro: Bertrand.

Rosendahl, Z. \& Corrêa, R. L. (1999). Manifestações da cultura no espaço. Rio de Janeiro: EdUERJ.

Rosendahl, Z. (2002). Espaço e religião: uma abordagem geográfica. Rio de Janeiro: EdUERJ.

Santos, G. E. O. (2000). Importância das peregrinações para o turismo mundial. Turismo em Análise, $11(2), 38-44$.

Santos, J. Z. (2005). Romaria de Nossa Senhora da Água Suja. Dissertação de Mestrado, Curso de Ciências da Religião, Departamento de Filosofia e Teologia, Universidade Católica de Goiás, Goiânia.

Serra, D. R. O. \& Tavares, M. G. C. (2016). Os fenômenos da peregrinação e do turismo em santuários e eventos católicos: uma análise sobre o Círio de Nazaré em Belém-PA. Cultur, 10(1), 143-168.

Souza, J. A. X. (2018). Geografia e Peregrinação. Caderno de Geografia, 28(54), 686-701.

Steil, C. A. \& Carneiro, S. S. (2008). Peregrinação, turismo e nova era: caminhos de Santiago de Compostela no Brasil. Religião \& Sociedade, 1 (28), 105-124.

Steil, C. A. (1996). O sertão das romarias: um estudo antropológico sobre o santuário de Bom Jesus da Lapa - Bahia. Petrópolis: Vozes.

Tomazini, L. (2019, 08 de julho). Romaria: Trindade recebeu mais de 3 milhões de romeiros na Festa do Divino Pai Eterno 2019. Jornal Opção. Recuperado de: https://www.jornalopcao.com.br/ ultimas-noticias/trindade-recebeu-mais-de-3-milhoes-de-romeiros-na-festa-do-divino-paiseterno-2019-195150/. Acesso em: 20/02/2020.

Túlio, S. (2019, 02 de julho). Trindade se prepara para multiplicar população em 24 vezes durante Festa do Divino Pai Eterno. Gl Globo. Recuperado de: https://gl.globo.com/go/goias/noticia/2019/07/02/ trindade-se-prepara-para-multiplicar-populacao-em-24-vezes-durante-festa-do-divino-pai-eterno. ghtml. Acesso em: 20/02/2020.

Contribuição de cada autor na construção do artigo

Alessandro Gomes Enoque: Concepção do objeto, fundamentação teórica, metodologia, análise dos resultados, redação do artigo, considerações finais.

Lorrana Laila Silva de Almeida: Concepção do objeto, fundamentação teórica, metodologia, pesquisa de campo, redação do artigo considerações finais. 